\title{
PROJETOS DE TURISMO EM TERRAS INDÍGENAS: Tremembé de Itapipoca e Jenipapo-Kanindé de Aquiraz - Ceará
}

\author{
Ms. Isis Maria Cunha Lustosa \\ Doutoranda no Programa de Pós-Graduação em Geografia da UFG \\ Campus Samambaia, Caixa Postal 131, CEP 74.001-970, Goiânia (GO), Brasil \\ Tel.: (+ 55 62) 35211184 - isismclustosa@hotmail.com
}

\begin{abstract}
RESUMO
Neste artigo discuto dois povos indígenas do estado do Ceará, no Nordeste brasileiro. Apresento à situação do povo Tremembé da comunidade Buriti e Sítio São José de Itapipoca, face ao projeto 'Nova Atlântida' - Cidade Turística e Residencial, empreendimento transnacional imposto a citada etnia indígena. Em seguida, menciono o povo Jenipapo-Kanindé de Aquiraz o qual acata um projeto de turismo em suas terras, considerado de auto-gestão e base comunitária. Para subsidiar as discussões propostas, a partir de produções acadêmicas da geografia humana enfoco o turismo e, por meio da antropologia trago algumas noções da etnologia indígena com ênfase para os povos indígenas do Nordeste. Completo o diálogo com dados da pesquisa documental e, especialmente os da pesquisa de campo. Esta última resultou nas múltiplas interpretações dos atores sociais entrevistados sobre a inclusão e exclusão dos povos indígenas em projetos de turismo no Brasil.
\end{abstract}

Palavras-chave: Povos indígenas, turismo, projetos, inclusão, exclusão.

\begin{abstract}
This article is about two indigenous peoples of Ceará state, in the Northeast region of Brazil. I present the situation of the Tremembé people of Buriti and Sítio São José communities in Itapipoca municipality, in relation to the 'Nova Atlântida' - Touristic and Residential City project, a transnational venture imposed on the cited indigenous people. Then I mention the Jenipapo-Kanindé people of Aquiraz municipality who have taken on a tourist project in their lands, considered to be self-management and community based. I subsidize the proposed discussions with academic productions of human geography, and I focus tourism, using anthropology, and bringing some notions from ethnology with Indigenous Peoples with an emphasis on Indigenous Peoples of the Northeast of Brazil. I complete the dialogue with data obtained from documental research and, especially, from field work. My field work brought multiple interpretations of the social actors interviewed, about the inclusion and exclusion of Indigenous peoples in tourist projects in Brazil.
\end{abstract}

Key words: Indigenous peoples, tourism, projects, inclusion, exclusion.

\section{RÉSUMÉ}

L'article concerne deux peuples autochtones du Ceará, État du Nord-Est brésilien: le peuple Tremembé, réparti en deux communautés, Buriti et Sítio São José (commune d'Itapipoca), confrontées au projet 'Nova Atlântida' - Cité touristique et résidentielle imposé par un promoteur immobilier transnational, et le peuple Jenipapo-Kanindé (commune d'Aquiraz), qui a accepté un projet touristique considéré comme autogéré et basé sur la communauté. À l'appui des discussions proposées, $\mathrm{j}$ 'ai recours à des travaux universitaires de géographie humaine sur le tourisme et à des notions d'ethnologie concernant plus particulièrement les peuples autochtones du Nord-Est brésilien. Ce dialogue est complété par des données tirées de recherches documentaires et, en particulier, de terrain. Ces dernières ont révélé les interprétations multiples des acteurs sociaux interviewés sur l'inclusion et l'exclusion des peuples autochtones par les projets touristiques au Brésil.

Mots-clés: Peuples autochtones, tourisme, projets, inclusion, exclusion.

\section{INTRODUÇÃO}

Esse artigo apresenta reflexões sobre os projetos de turismo em Terras Indígenas a partir das múltiplas interpretações sobre a inclusão e a exclusão dos povos indígenas nesse contexto. Baseio-me no projeto de doutoramento em Geografia intitulado 'Os povos indígenas e o turismo: um novo olhar sobre os Tremembé e os Jenipapo-Kanindé do Ceará' e nas leituras oriundas da geografia humana e sobre análises de sistemas interétnicos que possibilitou "a discussão de algumas contribuições da antropologia para a compreensão das relações interétnicas, dando ênfase a etnografias e debates 
sobre povos indígenas e Estados nacionais" (BAINES, 2008, p. 1). Enriqueço o diálogo, especialmente, com alguns autores da geografia brasileira que estudam o turismo e outros da antropologia, conhecedores da etnologia indígena, sobretudo aqueles que pesquisam sobre povos indígenas do Nordeste brasileiro. Ressalto que:

Os povos indígenas do Nordeste não foram objeto de especial interesse para os etnólogos brasileiros. Nas bibliotecas e no mercado editorial são muito raros os trabalhos especializados disponíveis. Apesar da grande expansão do sistema de pós-graduação nos últimos anos no Brasil, ainda no início desta década contava-se com poucas teses monográficas e nenhuma interpretação mais abrangente formulada sobre o assunto. Tudo levava a crer tratar-se, em definitivo, de um objeto de interesse residual, estiolado na contracorrente das problemáticas destacadas pelos americanistas europeus, e inteiramente deslocado dos grandes debates atuais da antropologia. Uma etnologia menor. (OLIVEIRA, 2004, p. 11).

Congrego-me aos que optam em pesquisar sobre os povos indígenas do Nordeste. Nesta região brasileira focalizo o Ceará, pois nesse estado ainda há quem negue a presença dos indígenas. Segundo Gomes e Vieira Neto (2009, p. 367) "até pouco tempo atrás, a história dos grupos indígenas estava silenciada na historiografia [...] consolidando idéias como no Ceará não há mais índios [...].” Para quem ainda renega a presença indígena no cerne da formação cearense, compensa ler que:

Índios são os que gritam com orgulho, para aqueles que não querem ouvir, eu sou Anacé, Gavião, Jenipapo-Kanindé, Kalabaça, Kanindé, Kariri, Pitaguary, Potyguara, Tabajara, Tapeba, Tremembé, Tupinambá, Tubiba-Tapuia [...] que não se escute mais que não há índios no Ceará [...]." (SILVA, 2009, p. 16-17, negritos da autora).

No decorrer do artigo destaco, principalmente, a situação enfrentada pelo povo Tremembé de Itapipoca, da comunidade Buriti e Sítio São José, em face da imposição do projeto 'Nova Atlântida' - Cidade Turística e Residencial em suas terras. Ressalto também a etnia Jenipapo-Kanindé de Aquiraz que se encontra inserida como integrante da Rede Cearense de Turismo Comunitário (REDE TUCUM) e adota um projeto de turismo na Aldeia Lagoa Encantada.

\section{O POVO TREMEMBÉ DE BURITI E SÍTIO SÃO JOSÉ, ITAPIPOCA - CEARÁ}

Antes de trazer a referida etnia indígena ao diálogo é importante, primeiramente, destacar que:

Os Tremembé já são cinco grupos vivendo em três municípios no Ceará: Itarema: Praia: 12 comunidades; Mata: 5 comunidades; Córrego João Pereira : 3 - Cajazeiras, São José e Capim Açu; Acaraú: duas comunidades: Queimadas e Telhas; Itapipoca: duas comunidades: São José e Buriti. [...]. (LEITE, 2009, p. 413).

Para localizar as comunidades do povo Tremembé de Itapipoca, se tomado como referência à cidade de Fortaleza, capital do estado do Ceará, "o acesso à terra indígena (TI) de São José e Buriti pode ser realizado pelas CE's -085 e 168 até a localidade de Marinheiros, de onde, através de estrada carroçável, a aproximadamente 4,0km encontra-se [...] Buriti.” (MEIRELES; MARQUES, 2004, p. 9). Dando continuidade do percurso, chega-se à comunidade Sítio São José. Esta, assim como Buriti, está localizada no município de Itapipoca no litoral oeste do Ceará. Suas paisagens apresentam:

O tabuleiro litorâneo, o ecossistema manguezal, as nascentes dos córregos, as lagoas perenes e sazonais, os campos de dunas e a faixa de praia [e ainda] as relações de subsistência com a biodiversidade que emana do sistema costeiro em análise. Neste sentido, comprovou-se a relação direta dos índios com as unidades de paisagem definidas, caracterizada por atividades ancestralmente relacionadas com o manejo [...] da terra. (MEIRELES; MARQUES, 2004, p. 4). 
De acordo com levantamentos encontrados no site do Conselho Indigenista Missionário (CIMI) - Regional Nordeste, a população Tremembé da comunidade Buriti e Sítio São José é em torno de 1316 habitantes, aproximadamente 186 famílias. Parte delas já cadastradas pela Fundação Nacional de Assistência a Saúde Indígena (FUNASA), conforme informação da liderança indígena da comunidade de Buriti (Erbene Rosa Veríssimo) e da comunidade de Sítio São José (Adriana Carneiro). Ainda assim, há discursos diversos, como exponho mais à frente, negando que existam índios nas duas comunidades. Pesquisas em antropologia esclarecem que:

Até pouco tempo atrás, o estado do Ceará, assim como os do Piauí e do Rio Grande do Norte, eram dados pelos registros da FUNAI e pelos levantamentos produzidos por antropólogos e missionários como os únicos estados do Brasil onde não haviam índios. No Ceará, entretanto, a presença indígena deixou de ser ignorada - ou melhor, passou a ser considerada - a partir da primeira metade da década de 1980 [...]. (BARRETO FILHO, 2004, p. 95).

Estudos realizados por Valle $(2004 ; 2005 ; 2007)$ evidenciam que os Tremembé do litoral do Ceará constituem uma população de mais de cinco mil pessoas. No decorrer dos séculos XVI e XVII, este povo indígena ocupava o litoral entre o Pará e o do Ceará. Invisibilizados como um grupo étnico no final do século XIX, vêm surgindo identidades Tremembé ao longo das últimas décadas. Esse processo foi pesquisado por Valle que usa a noção de 'campo semântico da etnicidade' para analisar os processos de reelaboração étnica.

Nas comunidades Buriti e Sítio São José - em que parte da população veio a se identificar como Tremembé (posteriormente à pesquisa de Valle concluída em 1991) - ser índio Tremembé tornou-se símbolo da resistência contra o 'Nova Atlântida' - Cidade Turística e Residencial. Para Meireles e Marques (2004, p. 4) “a implantação do complexo hoteleiro [...] irá interferir diretamente na disponibilidade dos recursos ambientais de subsistência e certamente na continuidade das manifestações culturais do grupo indígena." Contudo, o Governo Federal, o Governo Estadual do Ceará e o Governo Municipal de Itapipoca desejam destacar-se, no âmbito do turismo, com a implantação deste empreendimento turístico no país. Estas instâncias governamentais ocupam a posição de 'apoio institucional' no projeto 'Nova Atlântida', propagado como "el mayor Complejo Turístico mundial." (http://www.gruponovaatlantida.com/spain/index.htm). De fato, o "grupo espanhol Nova Atlântida [...] diz que a idéia é construir estrutura em condições de competir com destinos como Cancun, no Caribe, Punta Cana, na República Dominicana e Ibiza, na Espanha.” (MEIRELES; MARQUES, 2004, p. 53-54). Segundo revela a notícia ‘Cidade Nova Atlântica: embate ganha apoio político':

Com a crise imobiliária nos Estados Unidos e na Espanha, o Governo espanhol está se mexendo para investir no Brasil e no Ceará, por conta da proximidade geográfica, comenta o presidente da Agência de Desenvolvimento Econômico do Ceará (Adece), Antônio Balhmann. 'Para você ver como o Ceará vai bem: até o Cidade Nova Atlântida vai sair', completa o titular da Adece. (http://diariodonordeste. globo.com/cadernos/negocios).

Apesar do projeto 'Nova Atlântida' ter a sua implantação, no interior da comunidade Buriti e Sítio São José, impedida pelo Ministério Público Federal (MPF) desde o ano de 2004, as pressões para retomada do empreendimento permanecem, pois "desde 1979, uma empresa internacional tenta implantar nessa região um megaprojeto: uma cidade turística internacional.” (LEITE, 2009, p. 416). Como exemplo astucioso destas pressões, a notícia 'Nova Atlântida Aposta em Estratégia Ambiental' apresenta representantes do referido projeto adotando práticas que eles julgam ser uma forma de inclusão, como a 'Campanha de Preservação do Meio Ambiente'. Esta foi organizada pelo empreendimento ‘Nova Atlântida' e o ‘Afirma Grupo Espanhol Inmobiliário' com o propósito de permitir a participação dos alunos da localidade de Marinheiros em algumas atividades que:

Mercator - volume 9, número 20, 2010: set./dez. 
Além de palestra [...] tiveram oportunidade de visitar áreas de mangue e preservação, de aprender como se faz o plantio da muda e conhecer mais sobre o Empreendimento Nova Atlântida [...] Segundo Flávio Costa [...] 'Essa atividade é para tentar mostrar para as pessoas que as nossas ações aqui são para trazer o desenvolvimento. Nós estamos oferecendo mais de 80 empregos diretos. Tinha até gente que se dizia índio que negou sua origem e hoje trabalha com a gente e se diz mais feliz. Aqui em Itapipoca não tem índio', afirmou Flávio. (http://pib.socioambiental.org/pt/noticias?id=60517\&id pov=282).

A localidade de Marinheiros encontra-se adjacente a comunidades Buriti e Sítio São José. Esta proximidade se torna estratégica para os representantes do 'Nova Atlântida', pois realizam atividades, como a campanha descrita acima, com intuito de convencer moradores de Marinheiros sobre o desenvolvimento e oportunidades de empregos com a implantação da Cidade Turística e Residencial. Essas promessas de benefícios locais são formas de pressionar os moradores da citada localidade, contra aqueles que nas comunidades vizinhas, Buriti e Sítio São José, afirmam identidades étnicas e buscam os direitos às suas Terras Indígenas vislumbradas pelo 'Nova Atlântica'. O imponderado projeto ousa ocupar uma "superfície total de $31.260 .800 \mathrm{~m} 2$ [...] com playas, oasis naturales, lagos, rio navegable, [...] e exuberante vegetación tropical." (http://www.gruponovaatlantida.com/spain/index.htm). A apreciada área é primoroso motivo para representantes dos grupos privados internacionais e dos poderes públicos, parceiros no projeto 'Nova Atlântida', difundirem que não tem índios no Ceará e, muito menos, em Buriti e Sítio São José, comunidades providas de elementos naturais e, também de áreas litorâneas no entorno, correlativas as estruturas, os projetos e os serviços planejados para a Cidade Turística Residencial.

\section{O POVO JENIPAPO-KANINDÉ, ALDEIA LAGOA ENCANTADA, AQUIRAZ - CEARÁ}

Apesar de ainda haver quem conteste a existência de índios no Ceará, como relatado anteriormente e em vários outros trechos deste texto, ressalto que no caso dos Jenipapo-Kanindé, dados obtidos no site do Instituto Socioambiental (ISA) demonstram que Payaku indica uma vasta etnia a qual no século XVI ocupava totalmente a faixa sublitorânea que corresponde hoje os estados do Rio Grande do Norte e do Ceará.

Atualmente este povo é mais conhecido como os Jenipapo-Kanindé. O mesmo site por meio do link 'histórico do contato' também revela que:

Até o século XVIII, os Payaku habitavam os rios Açu, Apodi, Jaguaribe, Banabuiú e Choró. Por sua vez, os Jenipapo e Kanindé, semelhantes aos Tarairiú em língua e cultura, tal como os Payaku, viviam nas várzeas do Apodi, Jaguaribe e Choró. Como outros povos não-Tupi, eles ficaram conhecidos pela denominação genérica de "tapuias do Nordeste". Fontes históricas registram que, no Ceará, os primeiros contatos dos portugueses com estes povos ocorreram entre 1603 e 1608. Arredios e resistentes à colonização, eles sofreram violências, foram escravizados e perderam progressivamente suas terras. Rebelaram-se seguidamente até serem submetidos e quase totalmente dizimados, no decorrer da chamada "Guerra dos Bárbaros", entre 1680 e 1730. Em 1707, os Payaku foram aldeados por missionários jesuítas no rio Choró, em Aquirás, próximo de onde vivem hoje. Em 1764 a Aldeia dos Paiacús passou a chamar-se Monte-Mor-o-Velho, nome que perdurou até 1890. Na sede da aldeia criou-se a vila de Guarani (1890-1943), hoje município de Pacajus. Os Jenipapo e os Canindé foram aldeados entre 1731 e 1739 no rio Banabuiú, reunidos na Aldeia da Palma e depois em Monte-Moro-Novo-d'América (1764-1858), atual município de Baturité. (htpp://pib.socioambiental.org/pt/povo/ jenipapo-kaninde/634).

Assim, ao perguntar para alguma pessoa no município de Aquiraz, no estado do Ceará, sobre o povo Jenipapo-Kanindé, tive como resposta: são os índios da Lagoa Encantada da 'Pequena Cacique' (Maria de Lourdes da Conceição Alves). Esta liderança Jenipapo-Kanindé, na década de 1990, tornou-se a 'primeira mulher' a ocupar a função de Cacique no Brasil. De 1995 a 2010, a Pequena Cacique, representou a sua etnia nos 1.731 hectares da Aldeia Lagoa Encantada. A atual 
gestão encontra-se a cargo da sua filha, a Cacique Irê.

Então, para localizar a Terra Indígena do povo Jenipapo-Kanindé, partindo-se da cidade de Fortaleza pela rodovia estadual (CE 040) percorre-se $27 \mathrm{~km}$ até o município de Aquiraz, localizado na Costa Leste do litoral cearense. Depois, trafega-se mais $18 \mathrm{~km}$ até o destino do Iguape. A partir deste distrito, os $7 \mathrm{~km}$ restantes, em conservado trecho de estrada carroçável, permitem chegar "a Terra Indígena Lagoa Encantada, reconhecida em 2004 pelo Governo Federal.” (Maria de Lourdes da Conceição Alves, Pequena Cacique). Além desse dado, a liderança indígena referiu, na mesma data, que na aldeia são "96 famílias, 84 delas cadastradas e 16 aguardando para cadastrar, um total de mais ou menos quatrocentas e poucas pessoas." (Maria de Lourdes da Conceição Alves, Pequena Cacique). Saliento que o povo desta etnia está cercado pelas paisagens que agregam "componentes geoambientais, ecodinâmicos e culturais que se encontram atualmente à margem do fluxo turístico [...].” (MAGALHÃES; SILVA, 2010, p.12).

Em se tratando de turismo na aldeia, a Pequena Cacique e dois dos seus filhos, João Batista Alves e Eraldo Alves, congregam suas informações e expressam por meio da liderança indígena feminina que "nós conseguimo tirar a rede de empreendimento Aquiraz Resort daqui. Nele só campo de golfe ia ter vinte." (Maria de Lourdes da Conceição Alves, Pequena Cacique). A etnia Jenipapo-Kanindé não aceitou o turismo oriundo deste empreendimento. O filho da citada Cacique ressaltou que para as Terras Indígenas dos Jenipapo-Kanindé "tinham pensando em turismo de base comunitária, pois tivemos por 15 quinze dias, no ano de 2000, conhecendo a experiência de turismo dos Pataxó na Bahia." (Eraldo Alves, liderança indígena). Então, para implementar a atividade turística na Aldeia Lagoa Encantada, constituíram-se parcerias, como: a colaboração de estudantes e professores do Departamento de Geografia da Universidade Federal do Ceará (UFC) para junto aos jovens e adultos da etnia Jenipapo-Kanindé, prepararem os mapas etnográficos e definirem as trilhas ecológicas na Terra Indígena. Conforme está descrito no roteiro turístico da Aldeia Lagoa Encantada, nos levantamentos necessários para elaborá-lo foram caracterizados os aspectos culturais, bem como os locais referentes às atividades tradicionais e de usufruto da terra e, ainda, as variedades de paisagens com as delimitações dos ecossistemas. Neste trabalho conjunto foram identificadas as cinco trilhas (Lagoa Encantada, Morro do Urubu, Riachos, Roçados e Campo das Dunas) destinadas à visitação. Em cada uma delas destacaram-se os potenciais ambientais, ecológicos, culturais e econômicas da Aldeia Lagoa Encantada. Em toda a estruturação do roteiro turístico foi valorizado a integração da paisagem e da cultura do povo Jenipapo-Kanindé.

Surge assim o 'Projeto Educação Integral para a Sustentabilidade e o Desenvolvimento do Turismo Comunitário na Terra Indígena (TI) Jenipapo-Kanindé' fomentado pelo Programa Petrobras (Fome Zero - Desenvolvimento com Cidadania) e vinculado ao curso de (Graduação e ao Programa de Pós-Graduação em Geografia) da UFC. Por meio deste, a citada etnia é integrante da Rede de Turismo de Base Comunitária do Ceará (REDE TUCUM) a qual oferta diferentes roteiros turísticos envolvendo vinte comunidades de vários municípios do litoral leste e oeste do estado. Com o aludido projeto o povo Jenipapo-Kanindé se considera 'incluido' no processo de desenvolvimento do turismo em suas Terras Indígenas, pois "na tentativa de minimizar a entrada da especulação imobiliária para o turismo de massa a comunidade desenvolve o turismo comunitário." (MAGALHÃES; SILVA, 2010, p. 12).

Apesar desta etnia, em unanimidade, ter conseguido embargar a construção de um empreendimento turístico de padrão internacional e, não enfrentar conflitos internos entre seus habitantes no processo de reelaboração étnica, como ocorre entre o povo Tremembé de Buriti e Sítio São José, ainda assim o povo Jenipapo-Kanindé confronta-se com problemas decorrentes das pressões diretas e indiretas de grupos de empresários cearenses, como a Empresa Ypióca Agroindustrial. Segundo estes indígenas a citada empresa é causadora de danos ambientais na Lagoa Encantada. Para a etnia Jenipapo-Kanindé esta lagoa representa uma das principais simbologias da aldeia e, também se torna significativo atrativo do roteiro turístico, composto pelas cinco trilhas, anteriormente mencionadas, uma delas batizada de Trilha da Lagoa Encantada.

Mercator - volume 9, número 20, 2010: set./dez. 


\section{OS POVOS INDÍGENAS E OS PROJETOS DE TURISMO}

Os dois casos dos povos indígenas do estado do Ceará, enfocados no meu projeto de doutoramento, contrastam-se. Os Jenipapo-Kanindé apropriaram-se de um projeto de turismo e o desenvolvem em suas terras como estratégia de sobrevivência. Segundo liderança indígena desta etnia "a experiência de turismo na Aldeia Lagoa da Encantada não é aquele turismo de prostituição [...] que traga drogas, mas que saiba respeitar o índio [...] e que deixe recurso e benefício pra nós." (Maria de Lourdes da Conceição Alves, Pequena Cacique). Os Tremembé de Buriti e Sítio São José, diferentemente, estão se organizando como 'índios' para reivindicar seus direitos territoriais frente à ameaça de implantação do empreendimento turístico 'Nova Atlântida' em suas terras; lidando, portanto, com entraves para demarcá-las. Segundo Oliveira (1998, p. 21) "grande parte das terras habitadas pelos índios são reivindicadas por brancos, que sobre elas exibem títulos de propriedade ou alegam a aquisição de direitos de posse.” A situação das duas comunidades Tremembé é um exemplo, pois enfrentam as pressões do consórcio internacional de empresas que tenta implantar o 'Nova Atlântida' afirmando que detém a escritura destas terras desde a década de 1970, conforme consta na notícia intitulada 'Cidade Nova Atlântida: Embate Ganha Apoio Político':

As terras para a construção do megaprojeto Cidade Nova Atlântida, foram adquiridas, em 1978 pelo grupo empresarial espanhol de mesmo nome, durante o Governo de Virgílio Távora. Em 20 anos, muitas questões, barraram seu andamento. Investigado pelo Conselho de Controle de Atividades Financeiras (Coaf), vinculado ao Ministério da Fazenda, o presidente do grupo espanhol Nova Atlântida, Juan Ripoll Mari, foi acusado, em 2007, de lavagem de dinheiro do crime organizado internacional. Há seis meses, o Afirma Grupo Inmobiliário assumiu o comando do projeto. Orçada em US\$ 15 bilhões, a Cidade Nova Atlântida pretende ser o maior empreendimento turístico do País. Está prevista a construção de 13 hotéis cinco estrelas, 14 resorts, seis condomínios residenciais e três campos de golfe, numa área contínua de 12 quilômetros de praia e 3,1 mil hectares." (http://diariodonordeste.globo.com/cadernos/negocios).

Caso o 'Afirma Grupo Inmobiliário' consiga concretizar a construção do 'Nova Atlântida' nas Terras Indígenas dos Tremembé de Buriti e Sítio São José, a implantação deste empreendimento destruirá a interação entre estes povos indígenas e o seu ambiente. De acordo com os 'Estudos e Levantamentos Ambientais, Antropológicos e Arqueológicos' realizados nas comunidades Buriti e Sítio São José por Meireles e Marques (2004, p. 13), "serão promovidos impactos ambientais de elevada magnitude e relacionados diretamente com as atividades de usufruto da comunidade indígena (roçados, caça, acesso ao ecossistema manguezal e ao rio Mundaú para a pesca e a coleta de caranguejos e mariscos)." Significa suprimir o legado cultural do povo Tremembé das duas comunidades. Para Oliveira (2004, p. 25) trata-se do "patrimônio cultural dos povos indígenas do Nordeste, afetados por um processo de territorialização" que provoca o uso e apropriação dos seus espaços para a prática de atividades contemporâneas como o turismo.

Apesar da dimensão dos impactos espaciais decorrentes da construção do 'Nova Atlântida' nas duas comunidades Tremembé, aqui discutidas, estes povos ainda não conseguiram o reconhecimento das suas Terras Indígenas pelo Estado brasileiro. Parte dos moradores dessas comunidades se organiza como 'índios' para reivindicar seus direitos territoriais junto ao Estado frente à ameaça do empreendimento turístico. Outra parte está negando-se a se identificar como índios, pois cedem a cooptação dos salários ofertados pelo 'Nova Atlântida'. Segundo a liderança indígena Tremembé da comunidade Sítio São José, Adriana Carneiro, esta situação provoca conflitos nestas comunidades, até entre familiares. Em entrevista concedida à revista da Fundação Cepema, Adriana Carneiro, afirmou que:

Antes de a Nova Atlântida chegar, nós lutávamos juntos. Com a Nova Atlântida, começou esses empregos, então, o nosso povo não se identificou mais como índio. Porque se eles se identificarem, eles não vão ter mais os empregos da Nova Atlântida. Há um conflito entre se identificar e não se identificar." (AGROFLORESTA, 2008, p. 28). 
Ter as Terras Indígenas dos Tremembé de Buriti e Sítio São José reconhecidas significa perda para o Governo Estadual do Ceará e de seus correligionários políticos, favoráveis à implantação do 'Nova Atlântica', como revela a notícia ‘Embate Ganha Apoio Político':

Parlamentares da Comissão de Turismo da Câmara Federal, acompanhados pelo governador do Ceará, Cid Gomes (PSB) [...] sobrevoaram a área de três mil hectares que abrigará o empreendimento. Segundo eles, no local, não há rastro algum de indígenas. 'O que existe é uma ONG [Organização Não-Governamental] que já recebeu quase $\mathrm{R} \$ 1$ milhão para aliciar pessoas na região para se passarem por índios', afirma a Deputada Gorete Pereira (PR-CE). 'Fomos até lá, conversamos com a população local e não vimos nenhum índio. O que vimos foram pessoas que querem a implantação de um projeto que irá trazer desenvolvimento e empregos', emenda o deputado Albano Franco (PSDB-SE), presidente da Comissão de Turismo da Câmara Federal [...] Após a visita técnica à Itapipoca os deputados, o Embaixador da Espanha no Brasil, Ricardo Peidró e os espanhóis do Afirma Grupo Inmobiliario (atuais donos da Cidade Nova Atlântida desde o início de 2008) se reunirão a portas fechadas com Cid Gomes. (http://diariodonordeste.globo.com/materia.asp?aviso=yes\&codigo=555864).

No Brasil, os povos indígenas se encontram em situações muito diversas, desde povos com contatos seculares com a sociedade nacional, poucos povos que se mantêm afastados deste contato, e mesmo povos que estão se re-identificando como índios no intuito de garantir seus direitos às suas terras (MELATTI, 2007). Vale ressaltar que:

À diferença do que julga a opinião pública em sua maioria, os povos indígenas do Brasil não estão localizados apenas na Amazônia e no Brasil Central, lugares de acesso remoto em que a sociedade nacional ainda se expandia no século XX. Habitam também as mais antigas áreas de colonização do país, como o Nordeste [...] do país, constituindo-se não só como importantes atores políticos e interlocutores das políticas públicas, mas também inspirando estudos fecundos e interessantes formulações analíticas. (OLIVEIRA, 2004, p. 10)

As declarações acima prestadas por alguns dos parlamentares da Comissão de Turismo da Câmara Federal nas quais expressam não 'haver rastro algum de indígenas', assemelham-se a outra situação ocorrida no estado do Ceará com o povo Tapeba em que:

As declarações da deputada estadual Maria Lúcia Corrêa (PMDB), ex- primeira dama do município de Caucaia (1976-1980). Então presidente da Comissão de Educação da Assembléia Legislativa do Estado do Ceará, ela contestou, do alto do seu título de bacharel em história, a existência dos índios tapebas, manifestando contra o "sigilo" em que vinham se processando a ação no município e defendendo, em declaração à imprensa, a seguinte tese: Nunca existiu índios Tapebas. O que existe é um grupo de descendentes de um caboclo conhecido pela alcunha de "Perna-de-Pau" que habitou na área de Caucaia no início do século e que teria vivido maritalmente com duas irmãs, o que gerou um grupo racial fechado que foi habitar nas proximidades da Lagoa do Babaçu, na estrada da localidade de Garrote a oeste da sede da antiga Soure, hoje Caucaia [...]. (BARRETO FILHO, 2004, p. 128).

Para lideranças indígenas da comunidade Sítio São José, o Governo Estadual do Ceará interpreta que:

As terras indígenas são colocadas como antítese do desenvolvimento. Na formulação dos que se opõem à criação ou reconhecimento das áreas indígenas, seriam enormes extensões de terra, sem qualquer ocupação econômica produtiva, que se ergueriam como muralhas à expansão da economia de mercado. (OLIVEIRA, 1998, p. 43).

Esta concepção, por parte de alguns governantes, de que as Terras Indígenas sejam antíteses do desenvolvimento, torna-se evidente quando a liderança indígena Tremembé da comunidade Sítio São José, Adriana Carneiro, assegura na sua entrevista para a revista da Fundação Cepema que:

Mercator - volume 9, número 20, 2010: set./dez. 
O governador esteve aqui com o interesse de defender o Nova Atlântida. Ele querendo que nós negociássemos, deixássemos esse empreendimento acontecer. Que é pra trazer riqueza, trabalho para a população. O governador nos disse que terra pra ele tem que ser produtiva. Se não for, não vale nada. Ele estava dizendo aquilo para nos intimidar e que nós não teríamos outra opção. Mas, nós mostramos que ele é que vá fazer esse empreendimento em outro canto porque nós não vamos sair daqui. Nós temos que ficar aqui nas nossas terras. Se tem que vir turismo, se tem que haver desenvolvimento, que seja um desenvolvimento legal, estável para todos nós. Não um desenvolvimento que vai acabar com a maioria da nossa terra e deixar muito do nosso povo sem contato com os nossos manguezais, nossas matas e rios. (AGROFLORESTA, 2008, p. 28).

O Governo Estadual do Ceará não tem interesse em resguardar os $12 \mathrm{~km}$ de área contínua vislumbrados para a construção do 'Nova Atlântida'. Para Yazigi (2006, p. 131) “a corrida pelo desenvolvimento do turismo está se tornado uma obsessão nacional", ao ponto da faixa litorânea do estado do Ceará encontrar-se, praticamente, tomada pela especulação imobiliária para fins turísticos. De fato, os que governam o interesse pelo desenvolvimento não aceitam que:

Muitas vezes a criação de uma terra indígena é um instrumento essencial para a proteção ambiental, possibilitando, a preservação de um intricado equilíbrio entre fatores que viabilizam a coexistência de complexos ecossistemas [...] Logo, para avaliar a significação global (fundiária, populacional, cultural e ambiental) de uma terra indígena é fundamental pensar na diversidade ambiental que esta área abriga, assim como na complexa interação entre os ecossistemas e a população culturalmente diferenciada que a habita. (OLIVEIRA, 1999, p. 162).

Entre o povo Tremembé das comunidades Buriti e Sítio São José há os que lutam para se diferenciarem como 'índios' do restante da população regional, não somente frente às ameaças impostas pelo 'Nova Atlântida'. Mas, na luta pela posse de suas Terras Indígenas, pois vêem que:

El territorio indígena es un espacio apropriado por una comunidad, que tiene una interacción y materialización de su presencia en el territorio. En él, tienen sus viviendas, sus cultivos, sus caminos y plazas, sus lugares sagrados, sus recursos naturales como el agua y el bosque. Por consiguiente, su territorio no es solamente un espacio con dimensiones geométricas, sino un conjunto de elementos vinculados profundamente con el ser humano. (HIDALGO, 2006, p. 266).

O projeto de turismo imposto para ser implantado nas Terras Indígenas dos Tremembé de Buriti e Sítio São José pode ser comparado a um "processo violento de indigenismo empresarial que incorpora a dinâmica das pressões empresariais sobre os próprios índios." (BAINES, 1995, p. 128). Esse processo de exclusão revela-se em outro depoimento da liderança indígena de Sítio São José. Ela afirma: "antes do Nova Atlântida nosso espaço era saudável, a gente entrava e saia dele [...] principalmente à ida pro mangue pra pesca do carangueijo, caminho que hoje esta fechado pelo Nova Atlântida.” (Adriana Carneiro, Cacique Tremembé de Sítio São José).

\section{OS PROJETOS DE TURISMO EM TERRAS INDÍGENAS: OLHARES GEOGRÁFICOS E ANTROPOLÓGICOS}

Segundo Faria (2007, p. 298) “oficialmente no Brasil, não existe regulamentação, políticas e diretrizes que possam nortear a prática do Ecoturismo Indígena”, mesmo assim as demandas de projetos governamentais e/ou privados de turismo em Terras Indígenas, acendem sem ainda existir a regulamentação da Fundação Nacional do Índio (FUNAI) para o turismo no interior destas terras. No momento, prefiro não nomear que tipologia de turismo é essa. Outros autores chamam-no de 'turismo indígena'. Para Barreto; Burgos e Frenkel (2003, p. 17) "uma tipologia turística que pode ser valiosa para entender as diferenças de comportamento" dos povos indígenas em relação 
aos projetos de turismo em suas terras. Independente de como nomeá-lo, trata-se de um "tipo de turismo que no ha sido suficientemente investigado." (ULATE, 2006, p. 72). Entretanto, se este tipo de "turismo implicará em novas formas de colonização da paisagem natural e cultural ou se contribuirá na criação de novas possibilidades e horizontes para as comunidades locais, esta é uma questão aberta a discussões" (ALMEIDA, 2005, p. 343).

Nos debates da etnologia indígena brasileira, apesar de uma proliferação de temas mais diversos, constam poucas pesquisas referentes aos impactos dos projetos de turismo sobre os povos indígenas e/ou Terras Indígenas. Ressalto que:

LOS ESTUDIOS sobre el turismo enfocados desde una perspectiva [...] antropológica apenas se encuentran en una fase muy inicial en América Latina. Como corresponde a la primera infancia de un tema, sus primeros pasos son inseguros y tambaleantes. (ULATE, 2006, p. 72)

Para um dos primeiros etnólogos a debater o turismo em Terras Indígenas no Brasil por meio de pesquisa com o povo Pataxó do litoral da Bahia, "o turismo é um assunto pouco trabalhado pela antropologia, embora crescentes esforços se direcionem para esse tema." (GRÜNEWALD, 2001, p. 14-15). Considerando conforme Oliveira (2004, p. 16) que "os atuais povos indígenas do Nordeste são colocados como objeto de atenção pelos antropólogos”, certamente o turismo despertará interesse de pesquisa na etnologia indígena, pois alcança Terras Indígenas no Nordeste brasileiro, vislumbrado cada vez mais para o turismo.

Mediante estudos de alguns geógrafos observa-se que "o turismo avança célere pelos planaltos, cavernas, lagos, rios, cidades, fazendas, florestas, praias, museus, festas e cozinhas brasileiras, parece-nos que temos ainda que desvendar um pouco mais esta prática." (ALMEIDA, 2006, p. 121). A autora, em outra obra, considera que:

O turismo, no mundo globalizado, é uma fonte múltipla de revitalização demográfica, econômica, patrimonial e cultural. Neste caso, o turismo revela-se como um campo propício para a reprodução e a consolidação dos valores e interesses de grupos capitalistas privados e do Estado. São esses que definem o modelo de desenvolvimento turístico, isto é, o conjunto de estratégias desenhadas para alcançar objetivos determinados. Enfim, fonte de mais valia para alguns e de destruição para os outros, o turismo por mais ordinário que seja é, atualmente, um acontecimento simultaneamente revelador e misterioso. (ALMEIDA, 2003, p. 11).

Devido à complexidade do fenômeno turístico e às especificidades das culturas indígenas, reafirmo que se torna significativa esta reflexão sobre projetos de turismo em Terras Indígenas, pois o turismo é um "fenômeno complexo que envolve outros fenômenos sociais, culturais e econômicos da sociedade contemporânea." (LUCHIARI, 2000, p. 108). Dentro deste fenômeno tão intricado que é o turismo, as suas diversas faces são enfrentadas por povos indígenas de maneiras distintas. Ocorrem situações em que os projetos de turismo partem de iniciativas dos índios, interpretados por eles como forma de inclusão e fonte de renda para suprir suas necessidades. Em outras circunstâncias, existem projetos elaborados por grandes empresas que preterem as comunidades indígenas, tomando suas terras, sendo vistos pelos índios como uma ameaça para sua própria sobrevivência e como forma de exclusão.

\section{OS PROJETOS GOVERNAMENTAIS EIOU PRIVADOS DE TURISMO EM TERRAS INDÍGENAS}

O turismo, apesar de ser uma atividade ainda não regularizada pela FUNAI, é praticado em algumas das Terras Indígenas do Brasil. As segmentações do turismo são variadas e, nem todas as modalidades turísticas adequadas às paisagens das Terras Indígenas e as culturas de seus povos. Deste modo, algumas etnias indígenas preocupam-se com os impactos espaciais, culturais, sociais e

Mercator - volume 9, número 20, 2010: set./dez. 
econômicos decorrentes do turismo no cotidiano das suas aldeias. Vale ressaltar o avanço das experiências de projetos de turismo em Terras Indígenas mediante programas governamentais e acordos de cooperações internacionais com a "utilização de recursos externos". (SOUSA; SOUZA LIMA; ALMEIDA; WENTZEL, 2007, p. 7). Assim sendo, os primeiros projetos executados surgiram no Ministério do Meio Ambiente (MMA) por meio do Projeto Demonstrativos de Povos Indígenas (PDPI); do Subprograma Projetos Demonstrativos (PDA) e do Programa de Apoio ao Ecoturismo e à Sustentabilidade Ambiental do Turismo (Proecotur). O Subprograma PDA financiou na região Nordeste, entre o ano de 2007 e 2010, o projeto da Associação Pataxó de Ecoturismo (ASPECTUR), intitulado 'Programa de Desenvolvimento Sustentável e Preservação da Mata Atlântica na Reserva Indígena Pataxó da Jaqueira (PROJAQ).

Considerando que os Jenipapo-Kanindé antes de implementarem o projeto de turismo em suas Terras Indígenas, procuraram conhecer a experiência de turismo dos Pataxó do Litoral da Bahia, vale ressaltar conforme Grünewald (2001) que o citado povo Pataxó reinventou sua etnicidade, grande parte, em torno do turismo, assumindo um papel ativo na implementação de projetos de turismo. Este mesmo autor afirma que nessa experiência dos Pataxó do Litoral da Bahia "foram alguns índios que tomaram a iniciativa de gerar cultura, acionado especialmente como resposta ao turismo" (GRÜNEWALD, 2001, p.151). O projeto de turismo adotado pelo povo Pataxó do Litoral da Bahia e pelo povo Jenipapo-Kanindé do Ceará difere da situação dos Tremembé de Buriti e Sítio São José em que parte desses povos refuta o projeto de turismo e sente-se impactado pelo 'Nova Atlântida' que visa tomar suas terras e confiná-los em dois pequenos enclaves cercado pela obra do empreendimento turístico. Ou, em outras áreas fora das duas comunidades. Na entrevista concedida à revista da Fundação Cepema, a liderança indígena da comunidade Sítio São José, demonstra a indignação e o receio de perderem 'tudo' para a Cidade Turística Internacional. Segundo ela:

Tudo aqui é natural e a gente ver esse empreendimento querendo instalar uma cidade... Não é nem um projeto pequeno, mas é uma cidade. Transformar tudo que é nosso em cidade. E a gente ainda sente que tem o apoio do governo do estado, do município... Nós que moramos aqui e vivemos o dia-a-dia sentimos uma tristeza com esse empreendimento. (AGROFLORESTA, 2008, p. 28).

Conforme apresenta o site do 'Nova Atlântida' este é "o maior complexo turístico residencial do mundo". A referida informação reflete a ameaça que aflige o povo Tremembé de Buriti e Sítio São José. A notícia internacional intitulada "Brasil: Indígenas se Mobilizan Contra Complejo Turístico" demonstra a reação de alguns indígenas Tremembé das duas comunidades como está relatado:

Unos 200 indígenas pertenecientes a comunidades tremembés mantienen desde hace un mês un campamento para protestar contra la construcción de um complejo turístico a orillas del rio Mundaú, en el norteño estado de Ceará. La empresa de capitales españoles Nova Atlântida pretende construir ese centro turístico desde 2002, pero la oposición de los indígenas ha demorado el proyecto. Los manifestantes exigen que antes de avanzar con las obras, la estatal Fundación Nacional del Indio (FUNAI) demarque las tierras que pertenecen a los indígenas. Entienden que la llegada de los inversores constituye una "invasión a tierras ancestrales", y advierten que el atropello privado seguirá adelante si no intervienen los organismos gubernamentales. Una de las opositoras, Adriana Carneiro de Castro, denunció que las familias que están acampando con el propósito de impedir el transporte de materiales para las obras del complejo, están siendo víctimas de "permanentes amenazas" por parte de polícias contratados por la empresa. (www.radiomundoreal.fm/rmr/?q=es/node/2006)7.

Nas minhas pesquisas de campo às comunidades Tremembé do Ceará, no município de (Acaraú e Itarema) e Itapipoca, mantive o contato com lideranças indígenas. As suas declarações revelam cada vez mais os conflitos decorrentes do 'Nova Atlântida'. Em depoimento, a liderança indígena da comunidade Buriti comenta que teme o surgimento de novos conflitos e avanço das construções. Segundo ela, existe: 
Perto do sítio São José um empreendimento. Fizeram três almoxarifados de mudas de plantas. Eles não estão construindo os hotéis, mas estão trabalhando, oferecendo emprego pra comunidade. Vão começar outra construção. Essas benfeitorias impedem as terras indígenas. (Erbene Rosa Veríssimo, Cacique Tremembé de Buriti).

A planta do projeto 'Nova Atlântida' apresentada a mim pela referida Cacique, demonstra a intenção dos investidores e apoiadores deste empreendimento turístico em retirar o povo Tremembé de Buriti e Sítio São José de suas Terras Indígenas e encurralá-los nos dois pequenos enclaves propostos. Dessa forma, os investidores interpretam estarem beneficiando as comunidades numa inclusão social. Ofertam salários e se apropriam cada vez mais das áreas produtivas dessa Terra Indígena e dos seus elementos naturais fundamentais para eles (os investidores na beleza cênica) que precisam atrair os turistas, especialmente internacionais. Em outra declaração prestada a mim, em janeiro de 2007, a liderança indígena da comunidade Buriti afirma que os investidores desejavam:

Dar 1000 hectares para toda a comunidade morar e trabalhar. Não tem condições, uma casa emendada com as outras, como na cidade, uma casinha sem muda. Eles dão um salário, não é suficiente pra uma família. Não teria como cultivar, seria tudo comprado. (Erbene Rosa Veríssimo, Cacique Tremembé de Buriti).

Nas palavras de uma moradora da comunidade Buriti, revelam-se as tentativas da empresa de aliciar os habitantes destas duas comunidades. Ela informa:

O pessoal ganha quatrocentos reais por mês. Pagamento de quinze em quinze dias, sem carteira assinada. Férias, não se sabe se tem. A ocupação é de vigia, nas hortas. Aguando e adubando, tomando conta dos terrenos e das casas. Outros trabalham nos viveiros de camarão. Eles ocupam mais gente como vigia. (Luzia de Souza Carneiro, moradora em Buriti).

Outro morador da mesma comunidade assinalou: "aqui é o seguinte, a gente sabia sempre que o povo era índio, mas não podia falar [...] botavam a gente para correr. Meus avós, meus bisavós eram todos daqui. Não falavam que eram índios porque tinham medo." (Raimundo Carneiro de Souza, morador de Buriti). Este depoente acrescentou que:

Após o falecimento de Euclides Carneiro, que se dizia dono das terras, sua viúva arrumou documento falso e vendeu a um coronel de Trairí que vendeu para os espanhóis, há mais de vinte anos. Eles querem tomar tudo, e nós ficamos onde? A luta é meio difícil. Aqui está lutando índio contra índio. (Raimundo Carneiro de Souza, morador de Buriti).

Até aqui se constata que o turismo não tem obstáculos para alcançar os 'espaços' dos diferentes povos indígenas no Brasil. Estes projetos de turismo em Terras Indígenas são tomados como "novos objetos para atender os grandes investimentos [...] Esses objetos nem sempre estão relacionados às necessidades dos habitantes [...] da região, às vezes expulsos para dar lugar ao novo ente geográfico.” (LIMA, 2006, p. 101).

\section{CONSIDERAÇÕES FINAIS}

Os projetos de turismo em Terras Indígenas envolvem uma ampla variedade de fenômenos, desde iniciativas de povos indígenas de desenvolver estes projetos em suas terras para complemento da sua renda, a projetos impostos por grandes empresas e/ou governo, sem anteriormente consultar as populações atingidas. Nas comunidades Tremembé de Buriti e Sítio São José, o empreendimento turístico 'Nova Atlântida' - Cidade Turística e Residencial se configura como uma forma de turismo com investimentos internacionais consorciados que desconsidera os direitos constitucionais dos povos indígenas das duas comunidades. O interesse dos investidores ultrapassa os direitos dos 
índios. O processo de exclusão é evidente, pois em lugar de respeitar o 'espaço' e as relações sociais nas Terras Indígenas, que representam seus modos de vida, suas cosmologias e sua fonte de sobrevivência, o 'Nova Atlântida' estabelece relações altamente assimétricas com o povo Tremembé de Buriti e Sítio São José, aliciando alguns com salários para negar a identidade indígena e, desta maneira, criar conflitos internos.

Este consórcio de empresas que forma o 'Nova Atlântida' trata a Terra Indígena como se fosse "um quadro geométrico abstrato, um espaço puramente cartesiano. (CLAVAL, 2008, p. 40). Enganam-se, de fato, as Terras Indígenas devem ser interpretadas como um "espaço [...] amplamente modelado pelos seres humanos e por eles dotados de afetividade, como mostra a análise do sentido dos lugares ou dos diferentes significados do território." (CLAVAL, 2008, p. 40). Na interpretação de outro autor:

Uma sociedade indígena [...] constrói seu território como área controlada para usufruto de seus recursos, especialmente os recursos naturais [...] variável entre os diferentes grupos. Mas os referentes espaciais, aí, também fazem parte da vida dos índios como elementos indissociáveis, na criação e recriação de mitos e símbolos, podendo mesmo ser responsáveis pela própria definição do grupo enquanto tal. (HAESBAERT, 2006, p. 69):

$\mathrm{O}$ que discuto até o desfecho deste artigo reflete-se como mais uma abordagem acadêmica que averigua sobre os povos indígenas do Nordeste. Alguns destes povos já enfrentam os conflitos decorrentes dos recursos financeiros oriundos dos investimentos turísticos internacionais. Para Almeida (2003) o turismo revela-se como um campo propício a reprodução e à consolidação dos valores e interesses de grupos capitalistas privados e do Estado. São esses que definem o modelo de desenvolvimento turístico, isto é, o conjunto de estratégias desenhadas para alcançar objetivos determinados. Esta mesma autora considera que para outros estudiosos, o turismo tem seus aspectos negativos, como a destruição do ambiente, a poluição, a comercialização da cultura, a sobrecarga dos sítios, a perturbação das paisagens etc. Vejo que somente por meio de pesquisas etnogeográficas poder-se-ia revelar as complexidades de tais situações e os impactos do turismo sobre os povos indígenas e suas terras. Contudo, ainda há "reduzido valor e pouca credibilidade ao estudo das repercussões espaciais produzidas pelo turismo." (RODRIGUES, 1999, p. 78).

Neste artigo procurei continuar tecendo novas reflexões sobre os projetos de turismo em Terras Indígenas. Mesmo ainda tendo muito para pesquisar sobre o povo Tremembé das comunidades de Buriti e Sítio São José e o povo Jenipapo-Kanindé da Aldeia Lagoa Encantada, considero igualmente a Valle (2004, p. 340) que no "meu encontro etnográfico com essas pessoas [...] vivenciava algo extremamente novo, recente, e que pode ser entendido como um processo social de definição de uma unidade social."

\section{AGRADECIMENTOS}

Agradeço colaborações das lideranças indígenas (Adriana Carneiro, Erbene Rosa Veríssimo, Pequena Cacique, João Batista Alves e Eraldo Alves); dos moradores de Buriti (Luzia de Souza Carneiro e Raimundo Carneiro de Souza); de Maria Amélia Leite; de Stephen Grant Baines e de Jean François Cleaver. Ressalto que os depoimentos citados foram autorizados para uso em minhas publicações.

\section{REFERÊNCIA BIBLIOGRÁFICA}

AGROFLORESTA. 2008, nº 2. Fortaleza: Fundação Cepema, 2008.

ALMEIDA, Maria Geralda. (Org.) Paradigmas do turismo. Goiânia: Alternativa, 2003. 176 p.

ALMEIDA, Maria Geralda . A captura do Cerrado e a precarização de territórios: um olhar sobre sujeitos excluídos. In: ALMEIDA, MARIA GERALDA (Org.). Tantos Cerrados: múltiplas abordagens sobre a biogeodiversidade e singularidade sociocultural. Goiânia: Ed. Vieira, 2005. p. 321-347. 
ALMEIDA, Maria Geralda. A produção do ser e do lugar turístico. In: SILVA, JOSÉ BORZACCHIELLO DA; LIMA, LUIZ CRUZ; ELIAS, DENISE. (Orgs.). O Panorama da geografia brasileira 1. São Paulo: Annablume, 2006. p. 109-122.

BAINES, Stephen G. Os waimiri-atroari e a invenção social da etnicidade pelo indigenismo empresarial. Anuário Antropológico. 1995.

BAINES, Stephen G. Programa da disciplina de análises de sistemas interétnicos. Brasília: DAN/ICS/ UnB, 2008. 12 p.

BARRETO FILHO, Henyo Trindade. Invenção ou renascimento? gênese de uma sociedade indígena contemporânea do Nordeste. In: OLIVEIRA, JOÃO PACHECO DE. (Org.) A viagem da volta: etnicidade, política e reelaboração cultural no nordeste indígena. Rio de Janeiro: Contra Capa Livraria/LACED, 2004. 360 p.

BARRETTO, Margarita; BURGOS, Raúl; FRENKEL, David. Turismo, políticas públicas e relações internacionais. Campinas, SP: Papirus, 2003. 128 p.

BRASIL: INDÍGENAS SE MOBILIZAN CONTRA COMPLEJO TURÍSTICO. Disponível em: <http: www.radiomundoreal.fm/rmr/?q=es/node/2006>. Acesso em: 12 de nov. 2006.

CIDADE NOVA ATLÂNTICA: EMBATE GANHA APOIO POLÍTICO. Disponível em: < http://diariodonordeste.globo.com/cadernos/negocios>. Acesso em: 10 de nov. 2008.

CLAVAL, Paul. Geografia e dimensão espacial: a importância dos processos na superfície da terra. In: ALMEIDA, MARIA GERALDA; CHAVEIRO, EGUIMAR FELÍCIO; BRAGA, HELAINE DA COSTA. Geografia e cultura: a vida dos lugares e os lugares da vida. Goiânia: Editora Vieira, 2008. p. 17-43.

FARIA, Ivani de. Ecoturismo indígena como princípio de autonomia e afirmação cultural. In: SEABRA, GIOVANNI. (Org.). Turismo de base local: identidade cultural e desenvolvimento regional. João Pessoa: Editora Unversitária UFPB, 2007. p. 287-308.

GOMES, Alexandre Oliveira; VIEIRA NETO, João Paulo. Museus e memória indígena no Ceará: a emergência étnica entre lembranças e esquecimentos. In: PALITOT, ESTÊVÃO MARTINS. (Org.). Na mata do sabiá: contribuições sobre a presença indígena no Ceará. Fortaleza: Secult/Museu do Ceará/IMOPEC, 2009. p. 367-399.

GRÜNEWALD, Rodrigo de Azeredo. Os índios do descobrimento: tradição e turismo. Rio de Janeiro: Contra Capa Livraria. 2001. 224 p.

HAESBAERT, Rogério. O mito da desterritorialização: do "fim dos territórios" à multiterritorialidade. Rio de Janeiro: Bertrand Brasil, 2006. 400 p.

HIDALGO, Juan. Cosmovisión y participación política de los indígenas em el Equador. In: LEMOS, AMÁLIA INÊS G. DE; ARROYO, MÔNICA; SILVEIRA, MARIA LAURA. (Orgs.). América latina: cidade, campo e turismo. Buenos Aires: Consejo Latinoamericano de Ciências Sociais - CLASCO, São Paulo: USP, 2006. p. 263-280.

HISTÓRIA DO CONTATO. Disponível em: <http://pib.socioambiental.org/pt/povo/jenipapo-kaninde/634>. Acesso em: 21 de mar. 2009.

LEITE, Maria Amélia. Resistência Tremembé no Ceará - depoimentos e vivências. In: PALITOT, ESTÊVÃO MARTINS. (Org.). Na mata do sabiá: contribuições sobre a presença indígena no Ceará. Fortaleza: Secult/ Museu do Ceará/IMOPEC, 2009. p. 401-419.

LIMA. Luiz Cruz. Dinâmicas territoriais em espaços globais. In: SILVA, JOSÉ BORZACCHIELLO DA; LIMA, LUIZ CRUZ; ELIAS, DENISE. (Orgs.). O Panorama da geografia brasileira 1. São Paulo: Annablume, 2006. $368 \mathrm{p}$.

LUCHIARI, Maria Thereza D. P. Urbanização turística um novo nexo ente o lugar e o mundo. In: SERRANO, CELIA; BRUHNS, HELOÍSA TURINI; LUCHIARI, MARIA THEREZA D. P. (Orgs.). Olhares contemporâneos sobre o turismo. Campinas, SP Papirus, 2000. 206 p.

MAGALHÃES, Gledson Bezerra; SILVA, Edson Vicente da. Representação social no ensino de Geografia: o caso da escola indígena Jenipapo-kanindé. Geosaberes, Fortaleza, v. 1, n. 2, dezembro 2010.

MEIRELES, Antonio Jeovah de Andrade; MARQUES, Marcélia. Parecer Técnico: estudos e levantamentos ambientais, antropológicos e arqueológicos na Terra Indígena Tremembé de São José e Buriti, município de Itapipoca/CE. Fortaleza, dez., 2004, 98 p.

Mercator - volume 9, número 20, 2010: set./dez. 
MELATTI, Julio Cezar. Índios da América do Sul. Disponível em: <http://www.geocities.com/rainforest/ jungle/6885/ias.htm>. Acesso em mar. 2007.

NOVAATLÂNTIDA APOSTA EM ESTRATÉGIAAMBIENTAL. Disponível em: $<$ http://pib.socioambintal. $\mathrm{org} / \mathrm{pt} /$ notícias? $\mathrm{id}=60517 \& \mathrm{id}$ pov=282>. Acesso em: 12 de out. 2008.

NOVA ATLÁNTIDA CIDADE TURÍSTICA RESIDENCIAL. Disponível em: <http://www.gruponovaatlantida.com/spain/index.htm>. Acesso em:

OLIVEIRA FILHO, João Pacheco de. Redimensionanado a questão indígena no Brasil: uma etnografia das terras indígenas. In: OLIVEIRA FILHO, JOÃO PACHECO DE. (Org.). Indigenismo e territorialização: poderes, rotinas e saberes coloniais no Brasil contemporâneo. RJ, Contra Capa Livraria, 1998.

OLIVEIRA FILHO, João Pacheco de. Entrando e saindo da "mistura": os índios nos censos nacionais. In: OLIVEIRA FILHO, JOÃO PACHECO DE. (Org.). Ensaios em Antropologia histórica. Rio de Janeiro: Contra Capa Livraria/LACED, 1999. p. 124-151.

OLIVEIRA FILHO, João Pacheco de. Uma etnologia dos "índios misturados"? situação colonial, territorialização e fluxos culturais. In: OLIVEIRA FILHO, JOÃO PACHECO DE. (Org.). A viagem da volta: etnicidade, política e reelaboração cultural no nordeste indígena. Rio de Janeiro: Contra Capa Livraria/ LACED, 2004. p. 13-42.

RODRIGUES, Adyr Balastreri. Turismo e espaço: rumo ao conhecimento transdisciplinar. São Paulo: Hucitec. 1999. 158 p.

SILVA, Isabelle Braz Peixoto da. Prefácio. In: PALITOT, ESTÊVÃO MARTINS. (Org.). Na mata do sabiá: contribuições sobre a presença indígena no Ceará. Fortaleza: Secult/Museu do Ceará/IMOPEC, 2009. p. 15-17.

SOUSA, Cássio Noronha Iglez; LIMA, Antonio Carlos de Souza; ALMEIDA, Fábio Vaz Ribeiro de; WENTZEL, Sondra. (Orgs.) Povos indígenas: projetos e desenvolvimento. Rio de Janeiro: Contra Capa Livraria, 2007. $172 \mathrm{p}$.

ULATE, Allen Cordero. Nuevos ejes de acumulación y naturaleza: el caso del turismo. BUENOS Aires: Consejo Latinoamericano de Ciências Sociales-CLASCO, 2006. 224 p.

VALLE, Carlos Guilherme Octaviano do. Experiência e semântica entre os Tremembé do Ceará. In: OLIVEIRA, JOÃO PACHECO DE. (Org.) A viagem da volta: etnicidade, política e reelaboração cultural no nordeste indígena. Rio de Janeiro: Contra Capa Livraria/LACED, 2004. p. 281-342.

VALLE, Carlos Guilherme Octaviano do. Torém/Toré: tradições e invenção no quadro de multiplicidade étnica do Ceará comtemporâneo. In: GRÜNEWALD, RODRIGO DE AZEREDO. (Org.) Toré: regime encantado do índio do Nordeste. Recife: Fundação Joaquim Nabuco, Editora Massangana, 2005, p. 221-256. VALLE, Carlos Guilherme Octaviano do. Tremembé. Enciclopédia: Povos Indígenas no Brasil: ISA, 17 páginas. Disponível em: $<$ http://www.socioambiental.org/pib/epi/tremembe/print.htm $>$. Acesso em: $01 \mathrm{de}$ jun. 2007.

YAZIGI, Eduardo Abdo. Acertos metodológicos: relativismo cultural e turismo. In: SILVA, JOSÉ BORZACCHIELLO DA; LIMA, LUIZ CRUZ; ELIAS, DENISE. (Orgs.). O Panorama da geografia brasileira 1. São Paulo: Annablume, 2006. p. 131-136.

Trabalho enviado em novembro de 2010

Trabalho aceito em dezembro de 2010 